\title{
Demographic and socio-economic factors associated with multiple health risk behaviours among adolescents in Serbia: a cross sectional study
}

\author{
Katarina Boričić ${ }^{*}$, Snežana Simić ${ }^{2}$ and Jelena Marinković Erić ${ }^{3}$
}

\begin{abstract}
Background: The aim of this study was to examine the relationships between demographic and socioeconomic characteristics and engaging in multiple risk behaviours among adolescents in Republic of Serbia.

Methods: This study presents a cross sectional study of 683 adolescents aged 15 to 19 attending high school. The database from the 2006 National Health Survey was used. As a measure of demographic and socio-economic characteristics: age, type of settlement, family structure, having one's own room, school success and the household wealth index were used. Multivariate logistic regression model was performed.

Results: Boys were more than twice as likely to engage in multiple risk behaviours than girls. Adolescents who were older $(\mathrm{OR}=5.82,95 \% \mathrm{Cl}=3.21-10.54$, boys; $\mathrm{OR}=3.76,95 \% \mathrm{Cl}=1.77-7.99$, girls $)$ and adolescents who achieved low or moderate $(\mathrm{OR}=1.82,95 \% \mathrm{Cl}=1.02-3.26$, boys; $\mathrm{OR}=3.36,95 \% \mathrm{Cl}=1.51-7.44$, girls) school success had significantly higher risk than younger ones and those with high school success. Also, boys who came from a richer class households $(\mathrm{OR}=3.14,95 \% \mathrm{Cl}=1.02-9.66)$ and girls from incomplete family $(\mathrm{OR}=5.07,95 \% \mathrm{Cl}=2.06-12.50)$ had higher risk than boys from the poorest households and girls from complete family.

Conclusions: Further preventive interventions in Serbia should be gender and age specific, oriented towards older adolescents, those who have low or moderate school success, boys from richer class households and girls who live in incomplete families.
\end{abstract}

Keywords: Risk-taking, Socioeconomic factors, Demographic factors, Adolescent

\section{Background}

Adolescents' health presents a multi-value for themselves, their families and communities and a basis for sustainable development of every society and it depends on the efforts being made to preserve and improve it [1].

The category of adolescents covers the ages 10-19. Adolescents may, according to health indicators, be considered healthier than all other age groups, so the analysis of their health status should be health-oriented. However, due to many specific features of this period (sexual and psycho-physical development) and risk to

\footnotetext{
* Correspondence: katarina.boricic@gmail.com

${ }^{1}$ Center for Health Promotion, Institute of Public Health of Serbia "Dr Milan Jovanovic Batut", 5 Dr Subotic Street, 11000 Belgrade, Republic of Serbia
} Full list of author information is available at the end of the article take on dangerous behaviours that may jeopardize health it is necessary to assess the presence of these risk behaviours and to undertake adequate health educational interventions to promote healthy behaviour and life styles [2].

Risky behaviour can be defined as "voluntary behaviour that follows the existence of a specific objective and/or subjective degree of risk" or the "specific form of behaviour which has been shown to increase susceptibility to specific diseases or health disorders". In 1990, Irwin stated that these forms of behaviour should be called "risk-taking behaviour," because it involves adolescents who knowingly and willingly engage in situations where the risk is certain, and the outcome is unknown, but with a high probability to be negative for health [3].

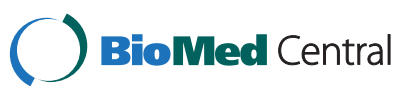


Generally, health risk behaviours tend to cluster together [4-6], and, in some adolescents, the clustering is sufficiently strong to develop a "risk behaviour syndrome" [7]. Risk behaviours in adolescents are multicausal behaviours. In this sense, it is considered that the effects of individual biological, psychological and sociological conditions, especially the family situation, and peer influence are important $[8,9]$.

The state of health of adolescents in the Republic of Serbia does not differ significantly in comparison to that of adolescents in the world, but there are, nonetheless, certain specificities. Namely, the last decade of 20th century in Serbia was marked by wars, economic sanctions of the international community and negative consequence which they caused and this in turn led to a disintegration of all segments of the society, including the family and school environment, as well as health care. Adolescents grew up in isolation, without appropriate social care, swamped by images of violence through the media, finding themselves in poverty they had not caused [2].

Most the previous studies in Serbia were exclusively focused on single risk factors [10-13]. This is the first study investigating the prevalence of concurrent health risk behaviours and its association with demographic and socio-economic determinants of health among adolescents in Serbia. Considering that, the results of this study can make a significant contribution to the provision of information to professional public and decision makers, especially on the importance of socio-economic and demographic determinants in the creation of public health programs whose implementation would contribute to reducing inequalities in adolescents' health.

The aim of this study was to examine the relationships between demographic characteristics and socio-economic status and engaging in multiple risk behaviours among adolescents in the Republic of Serbia.

\section{Methods}

\section{Population and sampling}

This study presents a cross sectional study of a sample of 683 adolescents aged 15 to 19 attending high school. The study used a database from the 2006 Health Survey of the Republic of Serbia (without data for Kosovo and Metohija), which was carried out by the Ministry of Health of the Republic of Serbia with financial and professional support of the World Bank, the World Health Organization Regional Office for Europe (country office Serbia) and the Institute of Public Health of Serbia 'Dr Milan Jovanovic Batut' [14].

The 2006 Health Survey of the Republic of Serbia provided statistically reliable estimates of the health indicators at the national level and at the levels of six geographic regions: Vojvodina, Belgrade, West, Central, East and South-East Serbia. By their further division into urban and rural areas, twelve areas were identified as the main sampling strata. The sample was selected in two stages. The primary stage units were 675 enumeration areas from the Census of 2002 in Serbia, selected on the basis of probability proportional sampling. Second stage units were households, selected by simple random sampling without replacement. After updating within each selected census enumeration areas, 10 households and 3 replacement households from the household list were chosen. The replacement households were interviewed only if some of the first 10 households were not found. In the case that a household refused to be interviewed, a replacement household was not contacted In this way, 7673 selected households were made sampling frame and observation units were all members of the selected households.

Out of 7673 households randomly selected for the sample, the members of 6156 households were interviewed. The household response rate was $86.5 \%$. In selected households, 683 adolescents aged 15 to 19 attending high school were identified.

Cross-sectional data were weighted to represent the Serbian population in 2002. The weights were adjusted by population projections for 2006 based on the vital statistics (birth and death rate).

\section{Ethical issues}

Informed consent was obtained from all respondents. The study was approved by the Review Board of the Ministry of Health of Serbia and the Institute of Public Health of Serbia.

\section{Instruments}

Three types of questionnaires were used to collect data: household questionnaire, questionnaire for children and adolescents aged 7-19 years (face to face) and selfadministered questionnaire for children and adolescents aged 12-19 years. Five questions that were related to demographic characteristics and socio-economic status of adolescents of the 81 questions from a face-to-face questionnaire and 6 questions that related to various forms of risky behaviour of the 66 questions from a selfquestionnaire for children and adolescents aged 12 to 19 were used. Socio-economic status was measured by calculating the demographic and health survey wealth index (wealth index) on the basis of answers to 9 questions from the household questionnaire that included 30 questions.

Data collection process was standardized in order to ensure the quality of data collection and that a consistent methodology would be used. Before the start of interviewing, training for 201 interviewers was conducted in the form of two-day workshops. The obligation of the interviewers was to interview all household members. 


\section{Data}

As a measure of demographic and socio-economic characteristics: age (categorized into two age groups: one - 15-16 and two - 17-19), type of settlement (one non-urban and two - urban), family structure (one complete: with both biological parents, with one biological parent and stepmother/stepfather or with caregivers, two - incomplete: with one biological parent, be alone or with grandparents), having one's own room (one - no and two - yes), school success (categorized into three groups: one - high (excellent, very good), two - moderate or low (good, sufficient, insufficient), and the household wealth index (one - poorest, two - poorer, three - middle, four - richer and five - richest class) were used. Assets included in computing household wealth index were number of bedrooms per household member, material used for floor, roof and walls of the house type of drinking water source and sanitation facilities, source of energy used for heating, possession of colour TV, mobile phone, refrigerator, personal computer, washing machine, dishwasher, air conditioning, central heating, car and internet access. The distribution of the household population by household wealth index was performed on 5 categories by $20 \%$ quintiles [15].

In secondary schools in Serbia, the evaluation of success in school for every student is performed using a five-point grading scale and it is assessed by averaging his grades in all subjects. At the end of the school year, final grades for each subject are calculated from those given at the end of each semester and they are determined by the following ranges: 5 (excellent) is given for an average of 4.50 to $5.00 ; 4$ (very good) is given for an average of 3.50 to $4.49 ; 3$ (good) is given for an average of 2.50 to $3.49 ; 2$ (sufficient) the lowest passing grade is given for an average of 2.00 to $2.49 ; 1$ (insufficient) the lowest possible grade, and the failing one, is given if the student does not have grade of at least 2 in each topic of the course.

Data on the prevalence of the single health risk among adolescents were assessed by the responses of adolescents about smoking at least one cigarette per day during the previous month, drinking any alcoholic beverage from the list of drinks: beer, wine, spirits, liqueur cocktail at least one day during the previous month, taking non-prescription tablets (anxiolytics, analgesics, amphetamine etc.) during the previous month, having the experience of casual sexual intercourse during the last 12 months, having first sexual intercourse before the age of 16 and bullying others. In order to determinate risk behaviour that related to bullying somebody, young people were asked whether they had taken part in insults, humiliation or physical harassment of another person during their lifetime. For further analysis, the adolescents were divided into three categories: no risk, one risk, and two or more health risk behaviours.

\section{Statistics}

Data were analysed by descriptive and inferential statistics. At the level of inferential statistics, nonparametric chisquare test was used for testing the statistical significance of the difference between the variables and multivariate logistic regression was used for statistical modeling separately for boys and for girls.

Distribution of boys and girls and their differences according to demographic and socio-economic status variables, single or various models of multiple health risk behaviours were examined by chi-square test or Fisher's exact test. Also, distribution of boys and girls with various models of health risk behaviours (no risk, one risk, and two or more health risk behaviours) and their differences according to demographic and socio-economic status variables were examined by chi-square test. Finally, multivariate logistic regression model was used to determine predictors of concurrent health risk behaviours. The dependent variable was engaging in multiple risk behaviours (two or more risk behaviours vs no risk behaviours). All analyses were done separately for boys and girls. The odds ratios (ORs) with their corresponding 95\% confidence intervals (CIs) were adjusted for age, type of settlement, household wealth index, family structure, having one's own room and school success.

Statistical package statistical software package SPSS 17 was used for data analysis. Differences were considered statistically significant at $\mathrm{P}<0.05$.

\section{Results}

\section{Sociodemographic factors and household wealth index}

There were more girls (51.6\%) than boys $(48.4 \%)$ in the sample. The mean age of the boys was $16.29 \pm 1.15$ and that of the girls was $16.32 \pm 1.12$. About sixty percent of them came from an urban environment during the time of the survey although the boys were slightly more likely to live in urban environment than the girls. More than ten percent (12.2\%) adolescents lived in the poorest households, while the majority of them (26.5\%) came from a household with the household wealth index four (richer adolescents).

Nearly three quarters of adolescents (72.3\%) had their own room, while more than four fifths of them $(88.4 \%)$ lived in complete families, slightly more boys than girls. Twice as many adolescents (63.8\%) achieved high success in school, significantly more girls than boys.

Significant difference was observed between gender and achieved school success. Compared with girls, boys reported significantly moderate or low school success (Table 1). 
Table 1 Distribution of boys and girls and their differences according to demographic and socio-economic variables, Serbia

\begin{tabular}{|c|c|c|c|c|}
\hline Variables & $\begin{array}{l}\text { Total } \\
\text { n (\%) }\end{array}$ & $\begin{array}{l}\text { Boys } \\
\text { n (\%) }\end{array}$ & $\begin{array}{l}\text { Girls } \\
\text { n (\%) }\end{array}$ & $\begin{array}{l}\text { Boys vs. Girls } \\
\text { p-value* }\end{array}$ \\
\hline Age & & & & .478 \\
\hline $15-16$ & $417(61.1)$ & $206(62.4)$ & $211(59.8)$ & \\
\hline $17-19$ & $266(38.9)$ & $124(37.6)$ & $142(40.2)$ & \\
\hline Settlement & & & & .807 \\
\hline Non-urban & $257(37.6)$ & $123(37.3)$ & $134(38.0)$ & \\
\hline Urban & $426(62.4)$ & $207(62.7)$ & $219(62.0)$ & \\
\hline Household wealth index & & & & .755 \\
\hline Poorest & $83(12.2)$ & $44(13.3)$ & $39(11.0)$ & \\
\hline Poorer & $140(20.5)$ & $65(19.7)$ & $75(21.2)$ & \\
\hline Middle class & $129(18.9)$ & $59(17.9)$ & $70(19.8)$ & \\
\hline Richer & $181(26.5)$ & $92(27.9)$ & $89(25.2)$ & \\
\hline Richest & $150(22.0)$ & $70(21.2)$ & $80(22.7)$ & \\
\hline Having one's own room & & & & .615 \\
\hline No & $189(27.7)$ & $88(26.7)$ & $101(28.6)$ & \\
\hline Yes & $494(72.3)$ & $242(73.3)$ & $252(71.4)$ & \\
\hline Family structure & & & & .603 \\
\hline Complete & $604(88.4)$ & $294(89.1)$ & $310(87.8)$ & \\
\hline Incomplete ${ }^{a}$ & 79 (11.6) & $36(10.9)$ & $43(12.2)$ & \\
\hline School success & & & & $<.001$ \\
\hline Low/moderate & $247(36.2)$ & $160(48.5)$ & $87(24.6)$ & \\
\hline High & $436(63.8)$ & $170(51.5)$ & $266(75.4)$ & \\
\hline
\end{tabular}

ancomplete family structure: with one biological parent, be alone or with grandparents ${ }^{*}$ Chi-square test.

Health risk behaviours

The prevalence of selected single health risk behaviour was computed separately for boys and girls. Boys more often than girls showed risky behaviour related to alcohol use, violence, sexual experience and smoking. On the contrary, girls more often reported taking tablets. Compared with girls, boys reported significantly currently using alcohol, bullying others, being sexual active during the last 12 months and having the first sexual experience before the age of 16 years (Table 2).

Table 2 Distribution of boys and girls and their differences according to single health risk behaviours, Serbia

\begin{tabular}{lllc}
\hline Variables & $\begin{array}{l}\text { Boys } \\
\text { n (\%) }\end{array}$ & $\begin{array}{l}\text { Girls } \\
\text { n (\%) }\end{array}$ & $\begin{array}{l}\text { Boys vs. Girls } \\
\text { p-value }\end{array}$ \\
\hline Alcohol use & $95(28.8)$ & $49(13.9)$ & .000 \\
Bullying others & $73(22.1)$ & $27(7.6)$ & .000 \\
Sexual activity & $71(21.5)$ & $38(10.8)$ & .000 \\
Cigarette use & $37(11.2)$ & $34(9.6)$ & .531 \\
Early sexual intercourse & $31(9.4)$ & $13(3.7)$ & .000 \\
Tablets use & $8(2.4)$ & $11(3.1)$ & .370 \\
\hline
\end{tabular}

${ }^{\text {"Chi-square test. }}$
The percentage of adolescents (20.3\%) was highest among those who reported one risk behaviour and decreased with increasing number of risk behaviours - it was lowest in the group of them who reported six risk behaviours. The distribution was similar in boys and girls. Boys more significantly reported two, three and four risk behaviours than girls (Table 3).

Table 4 presents the distribution of boys and girls with two and more risk behaviours. Among boys, the most

Table 3 Distribution of boys and girls according to various models of health risk behaviours, Serbia

\begin{tabular}{lllll}
\hline Variables & $\begin{array}{l}\text { Total } \\
\mathbf{n}(\%)\end{array}$ & $\begin{array}{l}\text { Boys } \\
\mathbf{n}(\%)\end{array}$ & $\begin{array}{l}\text { Girls } \\
\mathbf{n}(\%)\end{array}$ & $\begin{array}{l}\text { Boys vs. Girls } \\
\text { p-value }\end{array}$ \\
\hline No risk & $413(60.4)$ & $164(49.7)$ & $249(70.5)$ & .000 \\
One single risk & $139(20.3)$ & $75(22.7)$ & $64(18.1)$ & .003 \\
Two risks & $66(9.6)$ & $49(14.8)$ & $17(4.8)$ & .000 \\
Three risks & $51(7.5)$ & $29(8.8)$ & $21(5.9)$ & .009 \\
Four risks & $9(1.3)$ & $9(2.7)$ & $0(0.0)$ & .000 \\
Five risks & $6(0.9)$ & $4(1.3)$ & $2(0.6)$ & .181 \\
Six risks & $0(0.0)$ & $0(0.0)$ & $0(0.0)$ & - \\
\hline
\end{tabular}

* Chi-square test or Fisher's exact test. 
Table 4 Distribution of boys and girls with two and more health risk behaviours, Serbia

\begin{tabular}{|c|c|c|c|}
\hline Variables & Total n (\%) & Boys n (\%) & Girls n (\%) \\
\hline Alcohol use \& bullying others & $15(2.2)$ & $13(4.0)$ & $2(0.6)$ \\
\hline Alcohol use \& sexual activity & $12(1.8)$ & $11(3.4)$ & $1(0.3)$ \\
\hline Early sexual intercourse \& sexual activity & $10(1.5)$ & $6(1.8)$ & $4(1.1)$ \\
\hline Alcohol use \& cigarette use & $9(1.3)$ & $4(1.2)$ & $5(1.4)$ \\
\hline Sexual activity \& bullying others & $4(0.6)$ & $3(0.9)$ & $1(0.3)$ \\
\hline Tablets use \& bullying others & $3(0.4)$ & $3(0.9)$ & $0(0.0)$ \\
\hline Cigarette use \& sexual activity & $5(0.7)$ & $2(0.6)$ & $3(0.8)$ \\
\hline Cigarette use \& bullying others & $4(0.6)$ & $3(0.9)$ & $1(0.3)$ \\
\hline Alcohol use \& tablets use & $2(0.3)$ & $2(0.6)$ & $0(0.0)$ \\
\hline Alcohol use \& cigarette use \& sexual activity & $12(1.8)$ & $5(1.5)$ & $7(2.0)$ \\
\hline Alcohol use \& sexual activity \& bullying others & $10(1.5)$ & $8(2.4)$ & $2(0.6)$ \\
\hline Alcohol use \& early sexual intercourse \& sexual activity & $9(1.3)$ & $6(1.8)$ & $3(0.8)$ \\
\hline Alcohol use \& cigarette use \& bullying others & $6(0.9)$ & $4(1.2)$ & $2(0.6)$ \\
\hline Early sexual intercourse \& sexual activity \& bullying others & $5(0.7)$ & $4(1.2)$ & $1(0.3)$ \\
\hline Alcohol use \& tablets use \& bullying others & $2(0.3)$ & $0(0.0)$ & $2(0.6)$ \\
\hline Cigarette use \& early sexual intercourse \& sexual activity & $3(0.4)$ & $1(0.3)$ & $2(0.6)$ \\
\hline Cigarette use \& sexual activity \& bullying others & $1(0.1)$ & $1(0.3)$ & $0(0.0)$ \\
\hline Cigarette use \& tablets use \& bullying others & $2(0.3)$ & $0(0.0)$ & $2(0.6)$ \\
\hline Cigarette \& alcohol \& early sexual intercourse \& sexual activity & $5(0.7)$ & $5(1.5)$ & $0(0.0)$ \\
\hline Cigarette \& early sexual intercourse \& sexual activity \& bullying & $2(0.3)$ & $2(0.6)$ & $0(0.0)$ \\
\hline Cigarette \& Alcohol \& early sexual intercourse \& bullying others & $1(0.1)$ & $1(0.3)$ & $0(0.0)$ \\
\hline Alcohol use \& early sexual intercourse \& sexual activity \& bullying & $1(0.1)$ & $1(0.3)$ & $0(0.0)$ \\
\hline Cigarette \& alcohol \& early sex \& sexual activity \& bullying others & $5(0.7)$ & $4(1.2)$ & $1(0.3)$ \\
\hline Cigarette \& alcohol \& tablets \& early sex \& sexual activity & $1(0.1)$ & $0(0.0)$ & $1(0.3)$ \\
\hline Cigarette \& alcohol \& tablets \& early sex \& sexual activity \& bullying & $0(0.0)$ & $0(0.0)$ & $0(0.0)$ \\
\hline
\end{tabular}

common two risk behaviours were alcohol use and bullying others while alcohol use and cigarette use were among girls. When considering the distribution of adolescents with three risk behaviours, boys were most often reported alcohol use, being sexually active and bullying others while, cigarette, alcohol use and sexual activity were the most common risk behaviours among girls. A small percentage of adolescents involved in more than three health risk behaviours.

\section{Sociodemographic factors and health risk behaviours}

Table 5 presents the results of prevalence of concurrent multiple health risk behaviours among boys and girls by demographic characteristics and socio-economic status. The prevalence of multiple risk behaviours increased with age, living in urban environment, having one's own room, living in incomplete family and achieving moderate or low school success, for both sexes.

The prevalence of multiple health risk behaviours was significantly higher in older boys and boys who achieved moderate or low school success than the younger ones
( $45.2 \%$ vs. $17.0 \%, \mathrm{p}=.000$ ), and those with high success in school $(32.5 \%$ vs. $22.9 \%, \mathrm{p}=.031)$. Among girls, there was a significant difference between age groups: older girls were more likely than the younger ones $(17.6 \%$ vs. $7.1 \%, \mathrm{p}=.000$ ), family structure: girls from incomplete family were more likely than those from complete family (27.3\% vs. 9.1\%, p=.001), and school success: girls who achieved moderate or low school success were more likely than those with high success in school (19.5\% vs. $8.6 \%, \mathrm{p}=.014)$, to report multiple health risk behaviours (Table 5).

The results of multivariate logistic regression analyses of concurrent multiple health risk by demographic characteristics and socio-economic status are presented separately for boys and girls (Table 6). Multivariate logistic regression models showed a significant association of prevalence of concurrent multiple health risk behaviours with older age and with moderate or low school success in boys and girls and with incomplete family in girls and richer class households in boys. Adolescents who were older $(\mathrm{OR}=5.82$, boys; $\mathrm{OR}=3.76$, girls $)$ and adolescents 
Table 5 Distribution of various models of health risk behaviours by demographic and socio-economic variables, Serbia

\begin{tabular}{|c|c|c|c|c|c|c|c|c|}
\hline \multirow[t]{2}{*}{ Variables } & \multicolumn{4}{|l|}{ Boys } & \multicolumn{4}{|l|}{ Girls } \\
\hline & $\begin{array}{l}\text { No risk } \\
\text { n (\%) }\end{array}$ & $\begin{array}{l}\text { One risk } \\
\text { n (\%) }\end{array}$ & $\begin{array}{l}\text { Two or more } \\
\text { n (\%) }\end{array}$ & p-value ${ }^{*}$ & $\begin{array}{l}\text { No risk } \\
\text { n (\%) }\end{array}$ & $\begin{array}{l}\text { One risk } \\
\text { n (\%) }\end{array}$ & $\begin{array}{l}\text { Two or more } \\
\text { n (\%) }\end{array}$ & p-value ${ }^{*}$ \\
\hline Age & & & & .000 & & & & .000 \\
\hline $15-16$ & $127(61.6)$ & $44(21.4)$ & $35(17.0)$ & & $167(80.2)$ & $29(13.7)$ & $15(7.1)$ & \\
\hline $17-19$ & $37(29.8)$ & $31(25.0)$ & $56(45.2)$ & & $82(57.7)$ & $35(24.6)$ & $25(17.6)$ & \\
\hline Settlement & & & & .263 & & & & .453 \\
\hline Non-urban & $68(55.3)$ & $23(18.7)$ & $32(26.0)$ & & $96(71.6)$ & $27(20.2)$ & $11(8.2)$ & \\
\hline Urban & $96(46.4)$ & $52(25.1)$ & $59(28.5)$ & & $153(69.9)$ & $37(16.9)$ & $29(13.2)$ & \\
\hline Household wealth index & & & & .086 & & & & .508 \\
\hline Poorest & $24(54.5)$ & $12(27.3)$ & $8(18.2)$ & & $29(74.4)$ & $7(17.9)$ & $3(7.7)$ & \\
\hline Poorer & $40(61.5)$ & $9(13.8)$ & $16(24.7)$ & & $57(76.0)$ & $13(17.3)$ & $5(6.7)$ & \\
\hline Middle class & $28(47.5)$ & $13(22.0)$ & $18(30.5)$ & & $49(70.0)$ & $11(15.7)$ & $10(14.3)$ & \\
\hline Richer & $36(39.1)$ & $29(31.5)$ & $27(29.4)$ & & $58(65.2)$ & $21(23.6)$ & $10(11.2)$ & \\
\hline Richest & $36(51.4)$ & $12(17.1)$ & $22(31.5)$ & & $56(70.0)$ & $12(15.0)$ & $12(15.0)$ & \\
\hline Having one's own room & & & & .299 & & & & .165 \\
\hline No & $50(56.8)$ & $18(20.5)$ & $20(22.7)$ & & $78(77.2)$ & $14(13.9)$ & $9(8.9)$ & \\
\hline Yes & $114(47.1)$ & 57 (23.6) & 71 (29.3) & & $171(67.9)$ & $50(19.8)$ & $31(12.3)$ & \\
\hline Family structure & & & & .171 & & & & .001 \\
\hline Complete & $145(49.3)$ & $71(24.1)$ & 78 (26.6) & & $226(73.1)$ & $55(17.8)$ & $28(9.1)$ & \\
\hline Incomplete ${ }^{a}$ & $19(52.8)$ & $4(11.1)$ & $13(36.1)$ & & $23(52.3)$ & $9(20.5)$ & $12(27.3)$ & \\
\hline School success & & & & .031 & & & & .014 \\
\hline Low/moderate & $68(42.5)$ & $40(25.0)$ & $52(32.5)$ & & $53(60.9)$ & $17(19.5)$ & $17(19.5)$ & \\
\hline High & $96(56.5)$ & 35 (20.6) & $39(22.9)$ & & 196 (73.7) & 47 (17.7) & $23(8.6)$ & \\
\hline
\end{tabular}

Incomplete family structure: with one biological parent, be alone or with grandparents. ${ }^{~}$ Chi-square test.

who achieved low or moderate $(\mathrm{OR}=1.82$, boys; $\mathrm{OR}=3.36$, girls) school success had significantly higher risk for concurrent multiple health risk behaviours than younger ones and those who achieved high school success. Also boys who came from a richer class households $(\mathrm{OR}=3.14)$ and girls who live in incomplete family $(\mathrm{OR}=5.07)$ had significantly higher risk for concurrent multiple health risk behaviours in comparison with boys from the poorest households and girls from complete family (Table 6).

\section{Discussion}

Our study, however, showed that boys significantly more than girls demonstrated some single (currently using alcohol, currently smoking, being sexual active, having early sexual intercourse and bullying others) and concurrent multiple risk behaviours, which can be explained by the fact that such behaviour is often considered as socially acceptable for boys.

Previous studies on risk health behaviours by gender among adolescents have shown results similar to ours. The results of international cross sectional study "Health Behaviour in School-aged Children" (HBSC), showed clear evidence of differences by gender for risk-taking behaviour in almost all countries. Boys were more likely than girls to report they engage in risk behaviours on an experimental or regular basis. In the majority of countries, this was the case for alcohol and cannabis consumption, bullying and fighting. The patterns are less consistent for early sexual behaviour and smoking [8]. Results from the 2011 Youth Risk Behavior Survey (YRBS) indicated that among high school American students nationwide, the prevalence of having been in a physical fight, currently smoking, using alcohol and tablets were higher among male than female students, while older female students were more likely than male to report currently sexual activity [16]. The comparing of the results of the European School Survey Project on Alcohol and Other Drugs (ESPAD) on substance use among 15-16 year-old European students has shown that at the aggregate country level, with one exception - non-prescription use of tablets, slightly more boys than girls have reported having consumed alcohol and cigarettes in the past month, but the gender gap is very small between the 1995 and 2011 surveys [17]. Also, the results of two studies in China $[6,18]$ have shown that boys were more likely than girls to report they engage in multiple health risk behaviours. 
Table 6 Multivariate logistic regression of concurrent multiple health risk behaviours among boys and girls by demographic and socio-economic variables

\begin{tabular}{|c|c|c|c|c|}
\hline \multirow{3}{*}{ Variables } & \multicolumn{4}{|c|}{ Two or more risk behaviours vs. no risk behaviours } \\
\hline & \multicolumn{2}{|c|}{ Boys $n=(91$ vs. 164$)$} & \multicolumn{2}{|c|}{ Girls $n=(40$ vs. 249$)$} \\
\hline & Adjusted OR & $95 \% \mathrm{Cl}$ & Adjusted OR & $95 \% \mathrm{Cl}$ \\
\hline \multicolumn{5}{|l|}{ Age } \\
\hline $15-16$ & 1 & & 1 & \\
\hline $17-19$ & $5.82^{* *}$ & $3.21-10.54$ & $3.76^{* *}$ & $1.77-7.99$ \\
\hline \multicolumn{5}{|l|}{ Settlement } \\
\hline Non-urban & 1 & & 1 & \\
\hline Urban & 1.01 & $.51-1.99$ & 1.32 & $.55-3.18$ \\
\hline \multicolumn{5}{|c|}{ Household wealth index } \\
\hline Poorest & 1 & & 1 & \\
\hline Poorer & 1.31 & $.43-3.98$ & .76 & $.16-3.69$ \\
\hline Middle class & 2.22 & $.72-6.81$ & 1.73 & $.39-7.63$ \\
\hline Richer & $3.14^{* *}$ & $1.02-9.66$ & 1.45 & $.31-6.66$ \\
\hline Richest & 1.92 & $.60-2.67$ & 1.93 & $.41-9.08$ \\
\hline \multicolumn{5}{|c|}{ Having one's own room } \\
\hline No & 1 & & 1 & \\
\hline Yes & 1.36 & $.69-2.67$ & 1.60 & $.67-3.83$ \\
\hline \multicolumn{5}{|c|}{ Family structure } \\
\hline Complete & 1 & & 1 & \\
\hline Incomplete ${ }^{a}$ & 1.41 & $0.60-3.34$ & $5.07^{* *}$ & $2.06-12.50$ \\
\hline \multicolumn{5}{|l|}{ School success } \\
\hline Low/moderate & 1 & & 1 & \\
\hline High & $1.82^{*}$ & $1.02-3.26$ & $3.36^{* *}$ & $1.51-7.44$ \\
\hline
\end{tabular}

In general, many previous studies have confirmed the clustering of harmful lifestyles among adolescents [19-22]. Our study showed that the prevalence of multiple health risk behaviours significantly increased with age for both sexes. Similar results have been found in study conducted in Japan and the United States [23,24], while some other studies have shown that the prevalence of multiple risks increased with age for boys, but not for girls $[6,25]$.

In our study, boys and girls who were older and those who achieved low or moderate school success, boys from richer-class households and girls from incomplete family had significantly higher risk than those with high school success, boys from the poorest households and girls from complete family. The results of previous studies showed that living in an incomplete family [26-28], parental education $[29,30]$ and family affluence $[8,25,31]$ were associated with alcohol consumption. Weekly drinking tended to be more commonly reported among boys from high family affluence in some countries but in only a few for girls [8].
Also, the national study has shown an association between incomplete families [30] and smoking habits. On the contrary, results of the studies was conducted in a wide range of European countries, the US, Canada and Israel have showed that family affluence was not statistically associated with regular smoking in most countries [8,32].

The results from the 2009/2010 HBSC survey indicated that adolescents from less affluent families were more likely to smoke weekly in a minority of countries. Prevalence of experience of sexual intercourse was significantly lower among boys in high-affluence families in around a quarter and higher in only three, while for girls it increased with higher affluence in a few. Bullying others was linked to higher affluence in eastern countries and lower affluence in other regions [8].

This can be explained by the fact that adolescents from affluent families grow up in families that have only outward form of family (large apartment in which they live together) but not the classical form of internal closeness, connectedness and familiarity. Their parents are 
committed to their careers, acquiring material wealth and staying a little time at home. They are under increasing pressure to achieve excellent performance in school, in many extracurricular activities and social life. This way of life has a negative impact on adolescents' health. Where family affluence was not a significant influence on risk behaviour, it may be that other social influences arising from the family, peers and school had a greater impact during adolescence [33].

This analysis has several limitations. First, the crosssectional design makes it difficult to determine the direction of causality and the fact that the resulting link does not necessarily reflect the relationship between sociodemographic factors and any risky behaviour and risky behaviour among themselves. This limitation can be overcome with the use of longitudinal studies. A second methodological issue is with regard to the accuracy of the data collected through self-administered questionnaire. Consequently, the bias in the provision of data, is influenced on the one hand of sex of respondents (young men often exaggerate their experience while the girls reduced or diminished their experience) and on the other side of the sensitivity of the person due to past experiences related with certain risk behaviours. Finally, it should be mentioned that this study is based on eight year old survey and relates to a specific period of time and social context in Serbia. Despite the ongoing socio economic recovery of the country, the citizens of Serbia, during this period, still felt the consequences of the nineties that were marked by wars, sanctions and the collapse of all segments of society, including health care.

However, this is the first study investigating the prevalence of concurrent health risk behaviours and its association with demographic and socio-economic determinants of health among adolescents in Serbia and this fact creates a possibility to repeat this research with the same methodology and study design in order to follow up the trend of risk behaviours indicators over time. It could be used to estimate the effects of work on the reform and development of health systems Serbia and preserving and improving the health of adolescents, as well as in the creation of health policies whose implementation would contribute to reducing health inequalities.

\section{Conclusions}

This study has shown association between demographic characteristics and socio-economic status with multiple health risk behaviours among adolescents in Serbia. These findings should be an integral part of further preventive interventions which should be gender and age specific, oriented towards older adolescents and adolescents who have moderate or low school success, boys from richer class households and girls who live in incomplete families.

\section{Abbreviations}

GDP: The gross domestic product; Wealth Index: The demographic and health survey wealth index; SD: Standard deviation; OR: Odds ratio; Cl: Confidence Interval; HBSC: Health behaviour in school-aged children; YRBS: Youth risk behavior survey; ESPAD: The European school survey project on alcohol and other drugs; FAS: The family affluence scale.

\section{Competing interests}

The authors declare that they have no competing interests.

\section{Authors' contributions}

$\mathrm{KB}$ contributed to the study design, ran data analysis, and drafted the manuscript. SS contributed to analysis and interpretation of data, did critical revision of the article and supervised the research project. JM contributed to the statistical analysis and interpretation of data and did critical revision of the article. All authors read and approved the final manuscript.

\section{Acknowledgements}

This study is a part of the M.Sc. thesis that was defended in June 2010. at the Medical Faculty in Belgrade. There was no financial support. We would also like to thank Jasmina Grozdanov, MD, PhD, principal investigator in the 2006 National Health Survey for the population of Serbia for advice and providing access to the database.

\section{Author details}

${ }^{1}$ Center for Health Promotion, Institute of Public Health of Serbia "Dr Milan Jovanovic Batut", 5 Dr Subotic Street, 11000 Belgrade, Republic of Serbia. ${ }^{2}$ Institute of Social Medicine, Faculty of Medicine, University of Belgrade, Belgrade, Republic of Serbia. ${ }^{3}$ Institute of Medical Statistics and Informatics, Faculty of Medicine, University of Belgrade, Belgrade, Republic of Serbia.

Received: 3 July 2014 Accepted: 5 February 2015

Published online: 19 February 2015

\section{References}

1. The Ministry of Youth and Sport of the Republic of Serbia. National Strategy for Youth. Belgrade: Official Gazette of the Republic of Serbia; 2008.

2. The Institute of Public Health of Serbia "Dr Milan Jovanovic Batut". The health of population of Serbia - 1997-2007 analytical study. Zemun: Alta Nova; 2008.

3. Irwin Jr CE. The theoretical concept of at risk adolescent. Adolesc Med. 1990;1(1):1-14

4. Falk $\mathrm{D}, \mathrm{Yi}$ H, Hiller-Sturmhofel $\mathrm{S}$. An epidemiologic analysis of co-occurring alcohol and tobacco use and disorders: findings from the National Epidemiologic Survey on Alcohol and Related Conditions. Alcohol Res Health. 2006;29:162-71.

5. Weitzman ER, Chen YY. The co-occurrence of smoking and drinking among young adults in college: national survey results from the United States. Drug Alcohol Depend. 2005;80:377-86.

6. Sychareun V, Thomsen S, Faxelid E. Concurrent multiple health risk behaviors among adolescents in Luangnamtha province, Lao PDR. BMC Public Health. 2011;11:36.

7. Jessor R. Risk behavior in adolescence: a psychosocial framework for understanding and action. Dev Rev. 1992;12:374-90.

8. Currie C, Zanotti C, Morgan A, Currie D, de Looze M, Roberts C, et al. Social determinants of health and well-being among young people. Health Behaviour in School-aged Children (HBSC) study: international report from the 2009/2010 survey. Copenhagen: World Health Organization Regional Office for Europe; 2012.

9. Beal AC, Ausiello BA, Perrin JM. Social influences on health-risk behaviors among minority middle school students. J Adolesc Health. 2011;28:474-80.

10. Jeremić V, Matejić B, Soldatović I, Radenović S. Early sexual initiation and risk factors in Serbian adolescents: data from the National Health Survey. Eur J Contracept Reprod Health Care. 2014;19(3):211-9.

11. Terzic Supic Z, Santric Milicevic M, Sbutega I, Vasic V. The importance of family relations for cannabis users: the case of serbian adolescents. Iran J Public Health. 2013;42(3):249-60.

12. Golo DL, Cirić-Janković S, Santrić-Milićević M, Simić S. Alcohol use among adolescents in Serbia. Srp Arh Celok Lek. 2013;141(3-4):207-13. Serbian. 
13. Jovic-Vranes AS, Jankovic J, Vasic V, Jankovic S. Self-perceived health and psychological well-being among Serbian schoolchildren and adolescents: data from National Health Survey. Cent Eur J Med. 2011;6(4):400-6.

14. The Ministry of Health of the Republic of Serbia. Health survey of the population of Serbia 2006: main findings. Belgrade: Donat graf; 2007.

15. Rutstein SO, Johnson $\mathrm{K}$. The DHS wealth index. DHS comparative reports No. 6. Maryland, Calverton: ORC Macro; 2004. http://www.measuredhs.com/ pubs/pdf/CR6/CR6.pdf. Accessed 18 Feb 2014

16. Eaton DK, Kann L, Kinchen S, Shanklin S, Flint KH, Hawkins J, et al. Youth risk behavior surveillance - United States, 2011. MMWR Surveill Summ. 2012;61(4):1-162.

17. Hibell B, Guttormsson U, Ahlström S, Balakireva O, Bjarnason T, Kokkevi A et al. The 2011 ESPAD report - substance use among students in 36 European countries. Stockholm: The Swedish Council for Information on Alcohol and Other Drugs (CAN); 2012.

18. Xing $Y$, Ji CY. Co-occurrence of health-risk behaviors among Beijing middle school students China. J Adolesc Health. 2003:33(4):215-6.

19. Faeh D, Viswanathan B, Chiolero A, Warren W, Bovet P. Clustering of smoking, alcohol drinking and cannabis use in adolescents in a rapidly developing country. BMC Public Health. 2006;6:169.

20. Reddy P, Resnicow K, Omardien R, Kambaran N. Prevalence and correlates of substance use among high school students in South Africa and the United States. Am J Public Health. 2007;97:1859-64.

21. Siziya S, Muula AS, Kazembe LN, Rudatsikira E. Harmful lifestyles' clustering among sexually active in-school adolescents in Zambia. BMC Pediatr. 2008:8:6.

22. Muula AS, Herring P, Siziya S, Rudatsikira E. Bullying victimization and physical fighting among Venezuelan adolescents in Barinas: results from the Global School-Based Health Survey 2003. Ital J Pediatr. 2009:35(1):38.

23. Takakura M, Nagayama T, Sakihara S, Willcox C. Patterns of health-risk behavior among Japanese high school students. J Sch Health. 2001;71(1):23-9.

24. Brener ND, Collins JL. Co-occurrence of health-risk behaviors among adolescents in the United States. J Adolesc Health. 1998;22(3):209-13.

25. Liu A, Kilmarx P, Jenkins RA, Manopaiboon C, Mock PA, Jeeyapunt S, et al. Sexual initiation, substance use, and sexual behavior and knowledge among vocational students in northern Thailand. Int Fam Plan Perspect. 2006;32(3):126-35.

26. Andersen A, Holstein BE, Due P. School-related risk factors for drunkenness among adolescents: risk factors differ between socio-economic groups. Eur J Public Health. 2007;17(1):27-32.

27. Assanangkornchai S, Mukthong A, Intanont T. Prevalence and patterns of alcohol consumption and health-risk behaviors among high school students in Thailand. Alcohol Clin Exp Res. 2009;33(12):2037-46.

28. Heimisdottir J, Vilhjalmsson R, Kristjansdottir G, Meyrowitsch DW. The social context of drunkenness in mid-adolescence. Scand J Public Health. 2010;38(3):291-8.

29. Bachman JG, O'Malley PM, Johnston LD, Schulenberg JE, Wallace JM. Racial/ Ethnic differences in the relationship between parental education and substance use among U.S. 8th-, 10th-, and 12th-grade students: findings from the monitoring the future project. J Stud Alcohol Drugs. 2011;72(2):279-85

30. Grotvedt L, Stigum H, Hovengen R, Graff-Iversen S. Social differences in smoking and snuff use among Norwegian adolescents: a population based survey. BMC Public Health. 2008;8:322.

31. Richter M, Kuntsche E, de Looze M, Pförtner TK. Trends in socioeconomic inequalities in adolescent alcohol use in Germany between 1994 and 2006. Int J Public Health. 2013;58(5):777-84.

32. Zambon A, Lemma P, Dalmasso P, Borraccino A, Cavallo F. Socio-economic position and adolescents' health in Italy: the role of selfesteem and self-efficacy. Italian J of Public Health. 2007:4(3):220-6.

33. Settertobulte W, GaspardeMatos M. Peers and health. In: Currie C, Roberts C, Morgan A, Smith R, Settertobulte W, Samdal O, Barnekow Rasmussen V, editors. Young people's health in context: international report from the HBSC 2001/2002 survey. WHO policy series: health policy for children and adolescents, No.4. Copenhagen: WHO Regional Office for Europe; 2004. p. 178-83.

\section{Submit your next manuscript to BioMed Central and take full advantage of:}

- Convenient online submission

- Thorough peer review

- No space constraints or color figure charges

- Immediate publication on acceptance

- Inclusion in PubMed, CAS, Scopus and Google Scholar

- Research which is freely available for redistribution

Submit your manuscript at www.biomedcentral.com/submit 